\title{
PAH Formation and Soot Morphology in Flames of $\mathrm{C}_{4}$ Fuels
}

\author{
M. Schenk,${ }^{1 *}$ N. Hansen, ${ }^{2 *}$ H. Vieker, ${ }^{3}$ A. Beyer, ${ }^{3}$ A. Gölzhäuser, ${ }^{3}$ K. Kohse-Höinghaus ${ }^{1}$ \\ ${ }^{1}$ Department of Chemistry, Bielefeld University, D-33615 Bielefeld, Germany \\ ${ }^{2}$ Combustion Research Facility, Sandia National Laboratories, Livermore, CA 94551, USA \\ ${ }^{3}$ Department of Physics, Bielefeld University, D-33615 Bielefeld, Germany
}

\author{
accepted for presentation at the: \\ $35^{\text {th }}$ International Symposium on Combustion \\ "Soot, PAH and other large molecules" Colloquium
}

\begin{tabular}{lr}
\multicolumn{2}{c}{ Word Count (MS Word) } \\
Abstract: & 216 \\
Introduction: & 377 \\
Experimental Procedures: & 621 \\
Results and Discussion: & 1887 \\
Conclusions: & 192 \\
Acknowledgements: & 44 \\
41 References: & 751 \\
2 Tables: 68+61 & 129 \\
5 Figures: $156+148+385+524+315+660$ & 2188 \\
Total Words (excluding abstract): & $\mathbf{6 1 8 9}$
\end{tabular}

* Corresponding authors: nhansen@sandia.gov, +1 925-294-6272 (NH), marina.schenk@unibielefeld.de, +49 521-106-6308 (MS) 


\begin{abstract}
In this work, we describe experimental studies on the formation of polycyclic aromatic hydrocarbons (PAH’s) in opposed-flow atmospheric-pressure flames of $n$-butane, $i$-butane, $i$ butene, and i-butanol and on the morphology of nascent soot particles sampled from premixed atmospheric-pressure flames of the same fuels. To identify the major contributors to the molecular growth mechanism in opposed-flow flames, we employed flame-sampling molecularbeam mass spectrometry with electron ionization (EI) and in-situ gas-chromatography (GC) with mass spectrometric detection. The EI- and GC-EI mass spectra indicate that several pathways with different building blocks can contribute to molecular growth. Besides the commonly accepted hydrogen-abstraction- $\mathrm{C}_{2} \mathrm{H}_{2}$-addition steps, we found reactions of the methyl radical to be important steps. This observation is also supported by the complexity of the mass spectra which indicates that at least one of the building blocks is rather small. The importance of phenyl radicals as building blocks seems to be limited. We also sampled nascent soot particles from premixed atmospheric pressure flames of the above mentioned fuels and used helium-ion microscopy to unravel the influence of the fuel structure on the morphology of the sampled particles. While differences in flame temperatures and residence times are known to influence the particle sizes, the observed different morphologies are likely due to slightly different $\mathrm{C} / \mathrm{O}$ ratios and potentially the chemical nature of the fuel.
\end{abstract}




\section{Introduction:}

Understanding the chemical details of the soot formation in flames remains an intriguing problem in combustion chemistry research and significant progress has been made over the last few years. It is now believed that polycyclic aromatic hydrocarbons (PAH's) are the molecular precursors of soot particles [1, 2]. It is also accepted that the overall soot-forming chemistry starts with the formation of the so-called "first aromatic ring" with its formation dominated by reactions of resonantly stabilized radicals like propargyl, allyl, $i-\mathrm{C}_{4} \mathrm{H}_{5}$, and $\mathrm{C}_{5} \mathrm{H}_{5}$ [3-5]. The following molecular growth of the PAH's from benzene is generally described as a repetitive reaction sequence of a hydrogen abstraction followed by acetylene $\left(\mathrm{C}_{2} \mathrm{H}_{2}\right)$ addition [6, 7], but new experimental results and theoretical considerations throw doubt on the general validity of this so-called HACA mechanism [1, 2, 8, 9]. To develop a better understanding of the PAH growth chemistry, new experimental insights are necessary in order to guide the development and optimization of a validated and predictive combustion model.

In this paper, we present new experimental results with regards to the soot formation chemistry in laboratory-scale opposed-flow and premixed model flames fueled by $n$-butane, $i$ butane, $i$-butene, and $i$-butanol. The opposed-flow flames were analyzed with flame-sampling molecular-beam mass spectrometry employing electron ionization including isomeric separation of the PAH's based on gas chromatography [10]. Furthermore, we show helium-ion microscopy (HIM) images of nascent soot particles from laminar premixed atmospheric-pressure flames of the same fuels. The HIM technique $[11,12]$ allows for additional insights to the morphology of soot particles [13].

The purpose of this investigation is to obtain more experimental insights into the chemistry of soot formation and to provide an experimental basis for flame chemistry model 
development with regards to PAH growth. Extensive modeling, which is likely to be needed to interpret the shown experimental results in every detail, is beyond the scope of this paper. Keeping in mind that recent advances in combustion chemistry modeling have led to a detailed understanding of the small molecule chemistry in flames of these $C_{4}$ fuels $[10,14-16]$, we have shifted the focus of this work on the larger molecular species containing up to four condensed aromatic rings (pyrene). We also discuss the impact of the fuel structures on the morphology of the nascent soot $[13,17-19]$.

\title{
Experimental Procedures:
}

\author{
Gas-Phase Experiments:
}

Flame-sampling molecular-beam mass spectrometry (MBMS) has been established at Bielefeld University as a sophisticated tool to analyze laboratory-scale flames. The general concepts of this technique have been described previously $[10,14,20]$ and only a few details are provided here.

The typically used flat-flame burner was replaced with a home-built opposed-flow atmospheric-pressure flame system [21]. Fuel and oxidizer $\left(\mathrm{O}_{2}\right)$ were diluted in $\mathrm{Ar}$ and fed separately through two opposing outlets, which are $20 \mathrm{~mm}$ in diameter and kept $20 \mathrm{~mm}$ apart. An Ar shroud flow was used to minimize the effect of air intrusion. The flame gases were sampled via a microprobe with a $\sim 20 \mu \mathrm{m}$ orifice, similar to the experiments described by Skeen et al. [9, 22]. The non-premixed flames of this study offer the advantage that they can potentially produce PAH's in higher concentration compared to premixed flames. The conditions for the opposedflow atmospheric-pressure flames of $n$-butane, $i$-butane, $i$-butene, and $i$-butanol are given in Table 1. 
The used spectrometer consists of a two-stage Wiley-McLaren ion source with soft ionization using energetic electrons. The resulting molecular ions are separated in a reflectron time-of-flight unit which provides a mass resolution of $m / \Delta m \sim 2500$ and subsequently the ions are detected using a multi-channel plate with a multi-channel scaler for data recording. A schematic of the experimental set-up is included in the Supplementary Material.

To provide isomer-specific information for stable intermediates, which are not available from MBMS with electron ionization (EI) alone, we also performed probe-sampling in-situ gas chromatography (GC) and mass spectrometry experiments according to the procedures described in Ref. [10]. A low polarity column (Restek, Rxi-5Sil MS) was utilized in order to separate the commonly expected PAH intermediates. A GC program suitable for the separation of large hydrocarbons was applied, from $50^{\circ} \mathrm{C}\left(10 \mathrm{~min}\right.$ hold) to $300^{\circ} \mathrm{C}$ (heating rate $25^{\circ} \mathrm{C} / \mathrm{min}, 15 \mathrm{~min}$ hold, total duration 35 minutes). The identification was made with reference chromatograms obtained from the supplier [23, 24] and reference substances up to $m / z=128$. The column was chosen to allow separation of the most commonly expected isomers. The detection limit of the used GC-MS apparatus is around $10^{-4}$, thus very small isomer contributions may not be detected. In addition, reactive species, like fulvene derivatives, cannot be separated by chromatography due to their high reactivity; possible contributions of these species can thus not be fully excluded.

\section{Helium-ion microscopy (HIM):}

In addition to the gas-phase experiments, we used HIM [12] to gain insights into the morphology of soot particles, which we sampled from atmospheric-pressure burner-stabilized flames of the above mentioned $\mathrm{C}_{4}$ fuels $[13,25,26]$. For these experiments, sooting flames ( $\phi=2.04$ for all flames; see Table 2 ) were stabilized on a water-cooled, atmospheric-pressure 
porous plug burner and the soot particles were probed at two different heights, applying the thermophoretic sampling technique [26]. The use of two different burner systems has a simple reason: Because the thermophoretic sampling of particles is rather difficult in opposed-flow flames, we decided to apply premixed, burner-stabilized flames as a source for nascent soot particles, also following up on the work of Camacho et al. [19].

A silicon wafer (area $\sim 1 \mathrm{~cm}^{2}$ ) was mounted on a stepper motor and moved through the flame at the different heights. In HIM, a fine beam of helium ions is scanned pixel-by-pixel over a sample surface. It features a sub-nm resolution due to a small spot size $(0.25 \mathrm{~nm})$ and localized beam-sample interaction. Additional advantages are the high source brightness and low sample damage $[11,27]$. The experiments were conducted with a Carl Zeiss Orion Plus instrument. The working distance was held between 9.2 and $10.1 \mathrm{~mm}$, while a beam current of up to $0.9 \mathrm{pA}$ was applied. Secondary electrons were detected by an Everhart-Thornley detector.

\section{Results and Discussion:}

A typical result of the flame-sampling EI-MBMS experiments is shown in Fig. 1 for the mass range of $m / z=75-210$. This data was taken from within the $i$-butene flame near the sooting region. Similar looking mass spectra were obtained when sampling from within the other flames. The mass spectrum is quite crowded and it is obviously beyond the scope of the present paper to present detailed information in the form of quantitative isomeric composition for all of these intermediates.

Furthermore, it is important to note that the resolution of the mass spectrometer is not sufficient to separate polycyclic aromatic hydrocarbons from oxygenated near-mass species. This limitation precludes the identification of large oxygenated species, maybe anticipated to be 
present in the $i$-butanol flame, and for the following discussion we therefore assume that all observed mass peaks are due to the hydrocarbon species.

While quantitative mole fraction profiles and modeling results could potentially interpret the data in more detail, observed differences in the mass spectra, gas-chromatograms, and HIM images can be instructive as well. Only a few qualitative highlights are presented here and the conclusions drawn should be confirmed in the future with some help from modeling.

It is obvious from the complexity of the observed mass spectra that multiple pathways of more than one building block must be responsible for the molecular growth of the PAH molecules. This result is not surprising, considering the fact that multiple pathways can already contribute to the formation of the first aromatic ring, i.e. benzene $[5,28]$. Furthermore, the crowded mass spectra also indicate that at least one of the molecular building blocks must be rather small.

Besides the widely spread HACA mechanism several other pathways have been discussed in the recent literature describing the role of phenyl and methyl radicals [29-32]. For example, recent work of Apicella et al. [33] and Faccinetto et al. [34] has shown the relevance of small PAHs in soot formation, as these species are absent in the soot inception zone. In addition, Skeen et al. [9] have demonstrated the impact of fuel structure on PAH formation pathways.

Evidence for the molecular growth through methyl radicals is found in the sequences of mass peaks at repeating intervals of $14 \mathrm{amu}\left(+\mathrm{CH}_{3} /-\mathrm{H}\right)$. For example, such a sequence starts from benzene $(m / z=78)$ with the corresponding peaks of that sequence at $m / z=92,106,120$. Similar sequences can be found starting from indene $(\mathrm{m} / \mathrm{z}=116)$ or naphthalene $(\mathrm{m} / \mathrm{z}=128)$. Examples of the respective species profiles are shown in Fig. 2 for the sequences starting at $m / z=78$ and 128 . These sequences normally come to a stop after the addition of three or less 
methyl groups, thus maybe indicating a limited importance of this growth mechanism. However, Shukla et al. argue that in their pyrolysis experiments the most likely isomers on $\mathrm{m} / \mathrm{z}=106$ and 156 are the ethyl-substituted benzene or naphthalene rings rather than the dimethyl-substituted isomers [32]. Such an assignment would help to explain the prominent peaks at $m / z=104$ and 154, with the isomers styrene and vinyl-naphthalene (or acenaphthene) formed via dehydrogenation (or dehydrocyclization) from $m / z=106$ and 156, respectively. These conceivable routes are graphically summarized in Fig. 3. However, it seems rather unlikely that the second methyl addition happens only at the methyl-side rather than on the ring to form the di-methyl substituted isomer. Furthermore, it is worth mentioning that only the route via the 1-methyl- and 1-ethyl-naphthalene $(\mathrm{m} / \mathrm{z}=142$ and 156$)$ could lead to the acenaphthylene, but that the similar 2substituted isomers would react differently. These potentially additional pathways, for which experimental evidence is noted, do not exclude the known mechanisms of soot formation as e.g. the HACA route.

Results from the GC-experiments indicate that signal at $m / z=128,142$, and 152 can be assigned to contributions from naphthalene, methyl-naphthalene, and acenaphthylene. Examples of the GC-MS results are shown in Fig. 4. For all four flames similar chromatograms were obtained. The signal of $m / z=142$ (methylnaphthalene) was evaluated from the $i$-butene flame, but only very small contributions were observed in the $n$ - and $i$-butane flames. Possibly because of the lower overall PAH concentration in the $i$-butanol flame [14, 35], the isomers with $\mathrm{m} / \mathrm{z}=142$ and 152 could not be detected. Besides identifying naphthalene, methylnaphthalene, and acenaphthylene based on their elution time and mass-to-charge ratio, toluene, styrene, and indene were positively identified as main contributors to $m / z=92,104$, and 116 [23, 24]. 
No isomer-identifying GC-data exist for $m / z=154$ and 156 , but the isomers depicted in Fig. 3 seem plausible and could potentially explain the formation of the $\mathrm{C}_{12} \mathrm{H}_{8}$ isomers at $m / z=152$.

With regards to Fig. 3, we want to discuss two more important aspects. In addition to the shown $\mathrm{C}_{12} \mathrm{H}_{10}$ isomers, it seems fair to assume that biphenyl contributes to the signal at $m / z=154$. However, the relatively low intensity of this peak would indicate only a limited importance of the phenyl radical as a building block for PAH formation under the experimental conditions. This conclusion is also supported by the fact that in the GC-MS experiments biphenylene was not detected at $m / z=152$ and, as mentioned above, by the complexity of the mass spectra. However, concentrations of biphenyl may also be low because of its fast reactions with methyl or acetylene to form fluorene $\left(\mathrm{C}_{13} \mathrm{H}_{10}, m / z=166\right)$ or phenanthrene $\left(\mathrm{C}_{14} \mathrm{H}_{10}, m / z=178\right)$, both of which have been identified in the GC-MS experiments. Second, acenaphthylene ( $m / z=152)$, which was also identified in the GC-MS experiments, can be formed more efficiently through the HACA mechanism directly from naphthalene. This fact may again explain the relative height of the peak at $m / z=152$. Also, it has been established now that the HACA mechanism provides a facile route to five- and six-membered ring species via the sequences naphthalene $\rightarrow$ acenaphthylene $\rightarrow$ cylopenta[fg]acenaphthylene and biphenyl $\rightarrow$ phenanthrene $\rightarrow$ pyrene $[6,36,37]$. Both sequences are seen in our mass spectra and are also (at least partly) shown in Fig. 3.

The last reaction pathways to be discussed here are ring-enlargement reactions. It has been well established that fulvene can undergo a hydrogen-assisted isomerization reaction to form benzene [5, 38, 39]. Similar reactions seem conceivable for multi-ring structures and although these experimental results to do not provide direct evidence, these reactions should be tested in flame chemistry modeling of PAH growth. For example, the GC-experiments confirmed 
the presence of five-membered ring-structures at $\mathrm{m} / \mathrm{z}=116$ (indene), 152 (acenaphthylene), and 166 (fluorene). See Fig. 5 for more details. These species represent the main two types of fivemembered ring structures in $\mathrm{PAH}$ 's, the one with a saturated $\mathrm{CH}_{2}$ group (indene and fluorene) and the unsaturated one with only $\mathrm{CH}$ groups (acenaphthylene). An even more saturated ring (like in indane, $m / z=118$ ) seems plausible but no experimental confirmation can be provided here. Please note that the saturated $\mathrm{CH}_{2}$ group in indene and fluorene disturbs to some extent the resonance stabilization and that the respective radicals (with an $\mathrm{H}$ removed from the $\mathrm{CH}_{2}$ group) are entirely resonantly stabilized, thus very stable, structures. This fact seems to be responsible for the larger signal of these radicals (with respect to the neutral molecule) compared to the radicals (and neutral molecules) at $m / z=127(128), 151(152)$, and 177(178).

Figure 5 also indicates the presence of combustion intermediates with $m / z=130$, which could potentially be formed via methyl-addition/H-loss from indene ( $\mathrm{m} / \mathrm{z}=116)$, as well as the dehydrogenation step ending in the very stable naphthalene. A similar sequence starting at fluorene and ending at phenanthrene is shown as well. The unsaturated acenaphthylene reacts differently upon methyl addition to the five-membered ring and forms the unsaturated sixmembered ring structure $1 \mathrm{H}$-phenalene, another $\mathrm{C}_{13} \mathrm{H}_{10}$ isomer at $\mathrm{m} / \mathrm{z}=166$ (besides fluorene).

In general, the mass spectra seem to indicate that multiple pathways contribute to PAH formation in the flames of the four different $\mathrm{C}_{4}$ fuels and detailed modeling work is necessary to fully understand the flame-sampled mass spectra of the PAH's. Because the chemical growth mechanism will eventually lead from gas-phase molecules to nascent soot particles, we have studied the morphology of soot probed from the respective flames. While a detailed study about particle size distributions, geometric parameters, and chemical structure of the soot particle in these flames is an ongoing project and beyond the scope of the work shown here, we would like 
to present some experimental evidence for the influence of different chemical structures on the particles' morphology, especially the fractality. To this end, we employed HIM, recently shown to be an excellent tool for soot morphology studies [13].

A series of representative helium-ion micrographs for nascent soot particles probed at two different heights from a premixed $n$-butane flame and an $i$-butanol flame is shown in Fig. 6. An overview of particles probed from the four flames is shown in the Supplemental Material.

To enhance visibility of small particles, the contrast was enhanced following a step-bystep-procedure described in the Supplementary Material. For the soot sample probed at $0.8 \mathrm{~cm}$ distance from the burner surface of the $n$-butane flame, small particles (circles, pentagons) of around $8 \mathrm{~nm}$ diameter are visible, and some smaller particles start to grow into aggregates (rectangles). The instrument can detect particles smaller than $5 \mathrm{~nm}$. For the particles probed at $1.2 \mathrm{~cm}$ above the burner surface, the aggregates have grown into larger structures, while the small particles are still detectable. For the soot probed from the $i$-butanol flame at $0.8 \mathrm{~cm}$, the particles are in the range of below $8 \mathrm{~nm}$ in diameter. At $1.2 \mathrm{~cm}$ height in the $i$-butanol flame, the particles have larger diameters and are most probably aggregates that are formed from smaller particles. Their outer shape is less distinguished compared to the aggregates probed from the $n$ butane flame, instead they show a more elliptical or spherical shape, with a much smaller fractal dimension compared to the structures observed in the $n$-butane flame. Camacho et al. [19], who have recently studied slightly sootier flames of the $n$ - and $i$-isomers of butane and butanol in terms of impact of the fuel-bound oxygen on soot formation, reported that the maximum temperature of the burner-stabilized $n$-butane flame $(1750 \mathrm{~K} \pm 70 \mathrm{~K})$ is slightly lower compared to the temperature in an $i$-butanol flame with the same C/O ratio $(1790 \pm 50 \mathrm{~K})$, the same holds for the adiabatic flame temperature. The extensive work of Abid et al. [26] in combination with a 
very recent study by Schenk et al. [40] about soot formation in a set of canonical ethylene flames with varied maximum flame temperatures has shown that the temperature mainly influences the particle size, not the fractality of the particles.

With this background, the different morphology of the soot particles from the two flames may have two reasons. The cold gas velocity is slightly higher for the $i$-butanol flame (see Table 2), which directly correlates with the residence time, and the particles might thus be smaller as the reaction time is shorter. As a possible explanation for the different morphologies, especially the smaller fractal dimension in the $i$-butanol flame, the chemical differences in the flames, such as slightly different $\mathrm{C} / \mathrm{O}$ ratio or alternatively the influence of the fuel structure itself may come into play. For example, Alfé et al. [41] have investigated the difference between soots collected from flames of $\mathrm{CH}_{4}, \mathrm{C}_{2} \mathrm{H}_{4}$, benzene, and cyclohexane, and they have found a strong correlation between the nature of the fuel and the resulting nanostructure of the particles. It is likely that the different organization of the soot particles results from the combined effects of residence time and chemical environment in the flame.

\section{Conclusions:}

PAH growth and soot formation remain an intriguing problem in combustion chemistry research. In this study we have provided experimental evidence in the form of flame-sampling GC-EI-MS and EI-MBMS that multiple pathways contribute to the PAH formation in the flames of the $\mathrm{C}_{4}$ fuels $n$-butane, $i$-butane, $i$-butene, and $i$-butanol. Independent of the fuel-structure, the same building blocks seem to be responsible for the PAH growth in the different flames. Sequences in the mass spectra were observed which can result from the well accepted HACA mechanism and from various $\mathrm{CH}_{3}$ growth reactions, including $\mathrm{C}_{5}-\mathrm{C}_{6}$ ring-enlargement reactions. 
Methyl-substituted PAH's seem to be major intermediates and the importance of a small building block for PAH growth is also highlighted by the fact that the flame-sampled mass spectra are very complex. We find the different fractality of the nascent soot particles from within the different flames very intriguing, and the observed differences in the morphology of the sampled particles are likely the result of a combination of residence time and chemical environment in the flame. More detailed studies, including more experiments and flame chemistry modeling, are needed to provide a deeper understanding of the observed effects.

\section{Acknowledgements:}

The authors thank H. Waterbör for expert technical assistance. NH was in part supported by the Division of Chemical Sciences, Geosciences and Biosciences, Office of Basic Energy Sciences, U.S. Department of Energy under contract DE-AC04-94-AL85000. NH also acknowledges funding through the Alexander von Humboldt-Foundation. 


\section{References:}

[1] H. Bockhorn, A. D'Anna, A.F. Sarofim, H. Wang (Eds.), Combustion generated fine carbonaceous particles, KIT Scientific Publishing, Karlsruhe, 2009.

[2] H. Wang, Proc. Combust. Inst. 33 (2011) 41-67.

[3] C. S. McEnally, L. D. Pfefferle, B. Atakan, K. Kohse-Höinghaus, Progr. Energy Combust. Sci. 32 (3) (2006) 247-294.

[4] J. A. Miller, M. J. Pilling, J. Troe, Proc. Combust. Inst. 30 (2005) 43-88.

[5] N. Hansen, J. A. Miller, S. J. Klippenstein, P. R. Westmoreland, K. Kohse-Höinghaus, Combust. Expl. Shock 48 (5) (2012) 508-515.

[6] M. Frenklach, Phys. Chem. Chem. Phys. 4 (11) (2002) 2028-2037.

[7] M. Balthasar, M. Frenklach, Proc. Combust. Inst. 30 (2005) 1467-1475.

[8] A. Keller, R. Kovacs, K. H. Homann, Phys. Chem. Chem. Phys. 2 (8) (2000) 1667-1675.

[9] S. A. Skeen, H. A. Michelsen, K. R. Wilson, D. M. Popolan, A. Violi, N. Hansen, J. Aerosol Sci. 58 (2013) 86-102.

[10] M. Schenk, L. Leon, K. Moshammer, P. Oßwald, T. Zeuch, L. Seidel, F. Mauss, K. Kohse-Höinghaus, Combust. Flame 160 (3) (2013) 487-503.

[11] D.C. Bell, Microsc. Microanal. 15 (2009) 147-153.

[12] B.W. Ward, J.A. Notte, N.P. Economou, J. Vac. Sci. Technol. B 24 (2006) 2871-2874.

[13] M. Schenk, S. Lieb, H. Vieker, A. Beyer, A. Gölzhäuser, H. Wang, K. Kohse-Höinghaus, ChemPhysChem 14 (14) (2013) 3248-3254.

[14] P. Oßwald, K. Kohse-Höinghaus, U. Struckmeier, T. Zeuch, L. Seidel, L. Leon, F. Mauss, Z. Phys. Chem. 225 (9-10) (2011) 1029-1054. 
[15] N. Hansen, S. S. Merchant, M. R. Harper, W. H. Green, Combust. Flame 160 (11) (2013) 2343-2351.

[16] S. M. Sarathy, S. Vranckx, K. Yasunaga, M. Mehl, P. Oßwald, W. K. Metcalfe, C. K. Westbrook, W. J. Pitz, K. Kohse-Höinghaus, R. X. Fernandes, H. J. Curran, Combust. Flame 159 (6) (2012) 2028-2055.

[17] A. C. Barone, A. D'Alessio, A. D'Anna, Combust. Flame 132 (1-2) (2003) 181-187.

[18] C. Russo, M. Alfè, J.-N. Rouzaud, F. Stanzione, A. Tregrossi, A. Ciajolo, Proc. Combust. Inst. 34 (1) (2013) 1885-1892.

[19] J. Camacho, S. Lieb, H. Wang, Proc. Combust. Inst. 34 (1) (2013) 1853-1860.

[20] N. Hansen, T. A. Cool, P. R. Westmoreland, K. Kohse-Höinghaus, Prog. Energy Combust. Sci. 35 (2) (2009) 168-191.

[21] A. Brockhinke, A. Bülter, J. C. Rolon, K. Kohse-Höinghaus, Appl. Phys. B 72 (4) (2001) 491-496.

[22] S. A. Skeen, B. Yang, H. A. Michelsen, J. A. Miller, A. Violi, N. Hansen, Proc. Combust. Inst. 34 (2013) 1067-1075.

[23] Restek Corporation, "GC_EV00684" in Restek Searchable Chromatogram Library, http://www.restek.com/images/cgram/gc_ev00684.pdf.

[24] Restek Corporation, "GC_AR1157" in Restek Searchable Chromatogram Library, http://www.restek.com/images/cgram/gc_ar1157.pdf.

[25] A. D. Abid, J. Camacho, D. A. Sheen, H. Wang, Combust. Flame 156 (10) (2009) 18621870.

[26] A.D. Abid, N. Heinz, E.D. Tolmachoff, D.J. Phares, C.S. Campbell, H. Wang, Combust. Flame 154 (775-788) (2008). 
[27] D. Cohen-Tanugi, N. Yao, J. Appl. Phys. 104 (2008) 63504.

[28] N. Hansen, T. Kasper, B. Yang, T. A. Cool, W. Li, P. R. Westmoreland, P. Oßwald, K. Kohse-Höinghaus, Proc. Combust. Inst. 33 (2011) 585-592.

[29] B. Shukla, M. Koshi, Phys. Chem. Chem. Phys. 12 (10) (2010) 2427-2437.

[30] B. Shukla, M. Koshi, Combust. Flame 158 (2) (2011) 369-375.

[31] B. Shukla, M. Koshi, Combust. Flame 159 (12) (2012) 3589-3596.

[32] B. Shukla, A. Miyoshi, M. Koshi, J. Am. Soc. Mass Spectrom. 21 (4) (2010) 534-544.

[33] B. Apicella, A. Carpentieri, M. Alfè, R. Barbella, A. Tregrossi, A. Pucci, A. Ciajolo, Proc. Combust. Inst. 31 (1) (2007) 547-553.

[34] A. Faccinetto, P. Desgroux, M. Ziskind, E. Therssen, C. Focsa, Combust. Flame 158 (2) (2011) 227-239.

[35] C. K. Westbrook, W. J. Pitz, H. J. Curran, J. Phys. Chem. A. 110 (2006) 6912-6922.

[36] V. V. Kislov, A. I. Sadovnikov, A. M. Mebel, J. Phys. Chem. A. 117 (23) (2013) 47944816.

[37] M. Celnik, A. Raj, R. West, R. Patterson, M. Kraft, Combust. Flame 155 (1-2) (2008) $161-180$.

[38] N. Hansen, W. Li, M. E. Law, T. Kasper, P. R. Westmoreland, B. Yang, T. A. Cool, A. Lucassen, Phys. Chem. Chem. Phys. 12 (38) (2010) 12112-12122.

[39] A. W. Jasper, N. Hansen, Proc. Combust. Inst. 34 (2013) 279-287.

[40] M. Schenk, S. Lieb, H. Vieker, A. Beyer, A. Gölzhäuser, H. Wang, K. Kohse-Höinghaus, Proc. Combust. Inst. submitted (2014).

[41] M. Alfè, B. Apicella, R. Barbella, J.-N. Rouzaud, A. Tregrossi, A. Ciajolo, Proc. Combust. Inst. 32 (1) (2009) 697-704. 


\section{Tables:}

Table 1: Flame conditions for the opposed-flow atmospheric-pressure flames.

\begin{tabular}{|c|c|c|c|c|c|c|}
\hline \multirow[b]{3}{*}{ Fuel } & \multicolumn{3}{|c|}{ Fuel Stream } & \multicolumn{3}{|c|}{ Oxidizer Stream } \\
\hline & \multicolumn{2}{|c|}{ Mole Fractions } & \multirow{2}{*}{$\begin{array}{c}\text { Mass Flow } \\
\dot{\mathrm{m}} / \mathrm{g} \mathrm{cm}^{-2} \mathrm{~s}^{-1}\end{array}$} & \multicolumn{2}{|c|}{ Mole Fractions } & \multirow{2}{*}{$\begin{array}{l}\text { Mass Flow } \\
\dot{\mathrm{m}} / \mathrm{g} \mathrm{cm}^{-2} \mathrm{~s}^{-}\end{array}$} \\
\hline & $\mathrm{x}_{\mathrm{F}}$ & $\mathrm{x}_{\mathrm{Ar}}$ & & $\mathrm{x}_{\mathrm{O}_{2}}$ & $\mathrm{x}_{\mathrm{Ar}}$ & \\
\hline$n-\mathrm{C}_{4} \mathrm{H}_{10}$ & 0.06 & 0.94 & $3.2 \times 10^{-2}$ & 0.38 & 0.62 & $2.9 \times 10^{-2}$ \\
\hline$i-\mathrm{C}_{4} \mathrm{H}_{10}$ & 0.05 & 0.95 & $3.5 \times 10^{-2}$ & 0.38 & 0.62 & $2.9 \times 10^{-2}$ \\
\hline$i-\mathrm{C}_{4} \mathrm{H}_{8}$ & 0.04 & 0.96 & $3.4 \times 10^{-2}$ & 0.44 & 0.56 & $3.0 \times 10^{-2}$ \\
\hline$i-\mathrm{C}_{4} \mathrm{H}_{9} \mathrm{OH}$ & 0.07 & 0.93 & $3.6 \times 10^{-2}$ & 0.38 & 0.62 & $2.9 \times 10^{-2}$ \\
\hline
\end{tabular}

Table 2: Flame conditions for the burner-stabilized atmospheric premixed flames.

\begin{tabular}{cccccc}
\hline \multirow{2}{*}{ Fuel } & \multicolumn{3}{c}{ Mole fractions } & Equivalence & Cold Gas Velocity \\
& Fuel & Oxygen & Argon & Ratio $\phi$ & {$[\mathrm{cm} / \mathrm{s}]$ at 300K } \\
\hline$n-\mathrm{C}_{4} \mathrm{H}_{10}$ & 0.0959 & 0.3043 & 0.5998 & 2.04 & 3.593 \\
$i-\mathrm{C}_{4} \mathrm{H}_{10}$ & 0.0959 & 0.3043 & 0.5998 & 2.04 & 3.593 \\
$i-\mathrm{C}_{4} \mathrm{H}_{8}$ & 0.1022 & 0.3043 & 0.5998 & 2.04 & 3.593 \\
$i-\mathrm{C}_{4} \mathrm{H}_{9} \mathrm{OH}$ & 0.0959 & 0.3043 & 0.5998 & 2.04 & 3.948 \\
\hline \hline
\end{tabular}




\section{Figures:}

Figure 1: (145+11=156 words)

Flame-sampled mass spectrum from within the atmospheric-pressure opposed-flow $i$-butene diffusion flame.

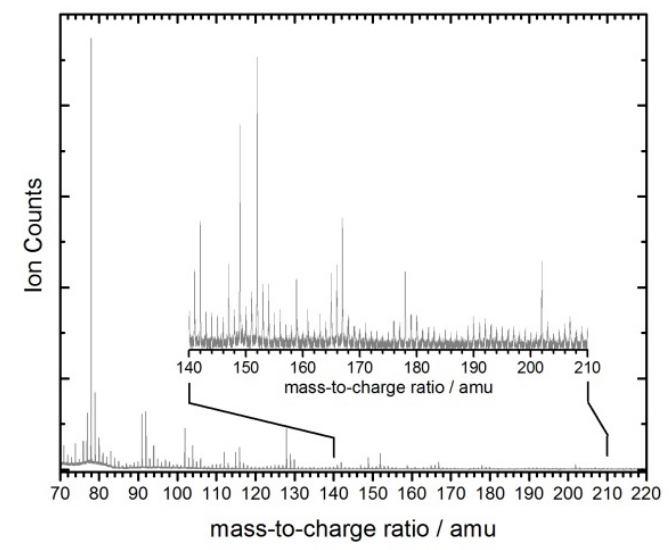




\section{Figure 2: (130+18=148 words)}

Species profiles as function of distance from the fuel outlet for methyl-addition sequences starting at $m / z=78$ and 128 .

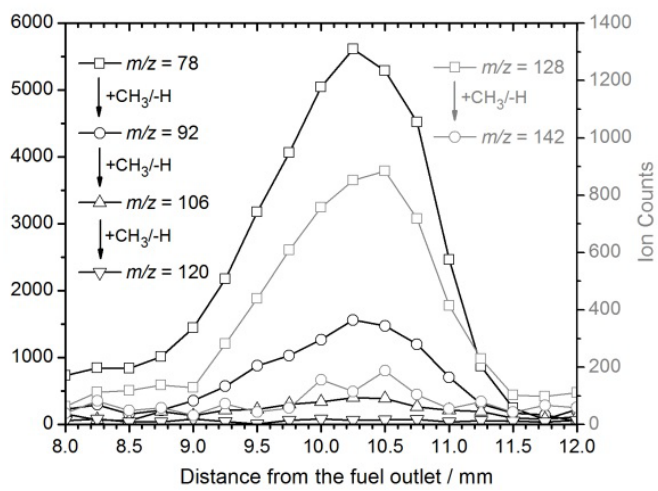




\section{Figure 3: $(355+30=385$ words $)$}

Mass spectra and conceivable formation pathways of certain isomers. Naphthalene, methylnaphthalene and acenaphthylene (at $m / z=128,142$, and 152) have been positively identified using the GC experiments. See text for details.

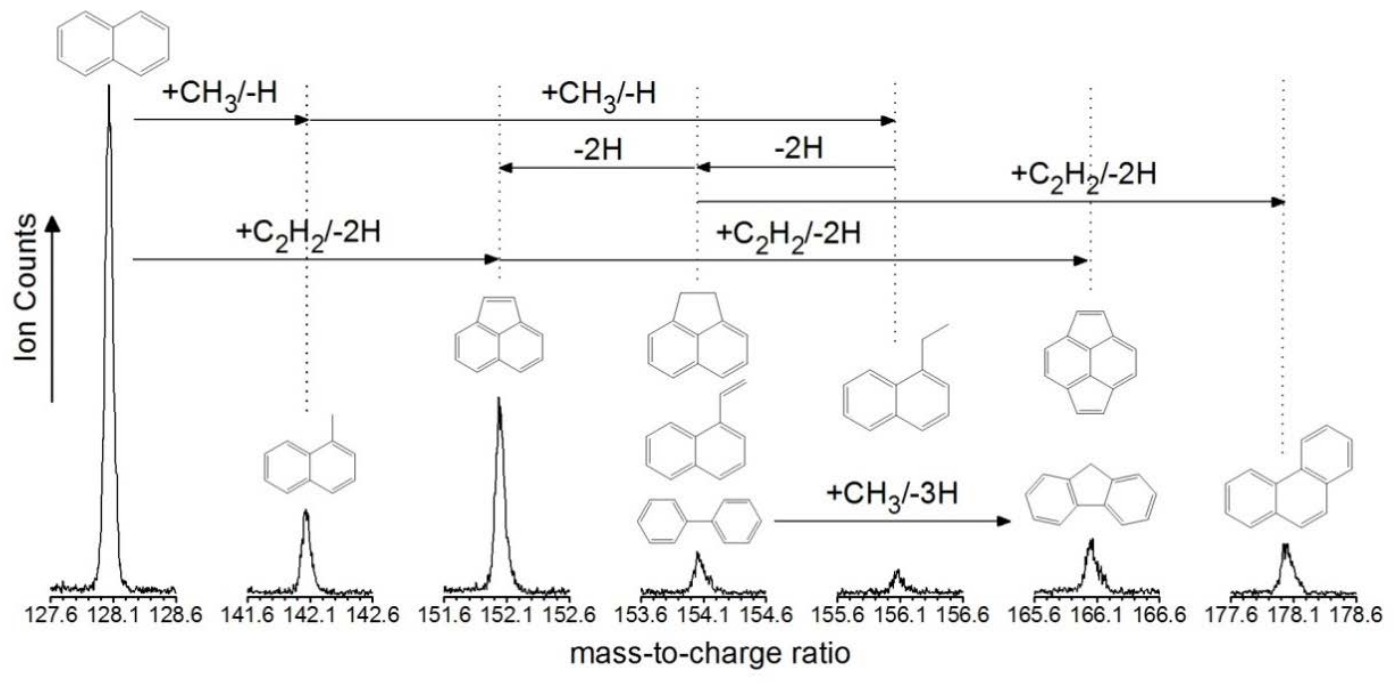


Figure 4: $(513+11=524$ words $)$

GC-MS spectra obtained from the flame zones of the four flames.
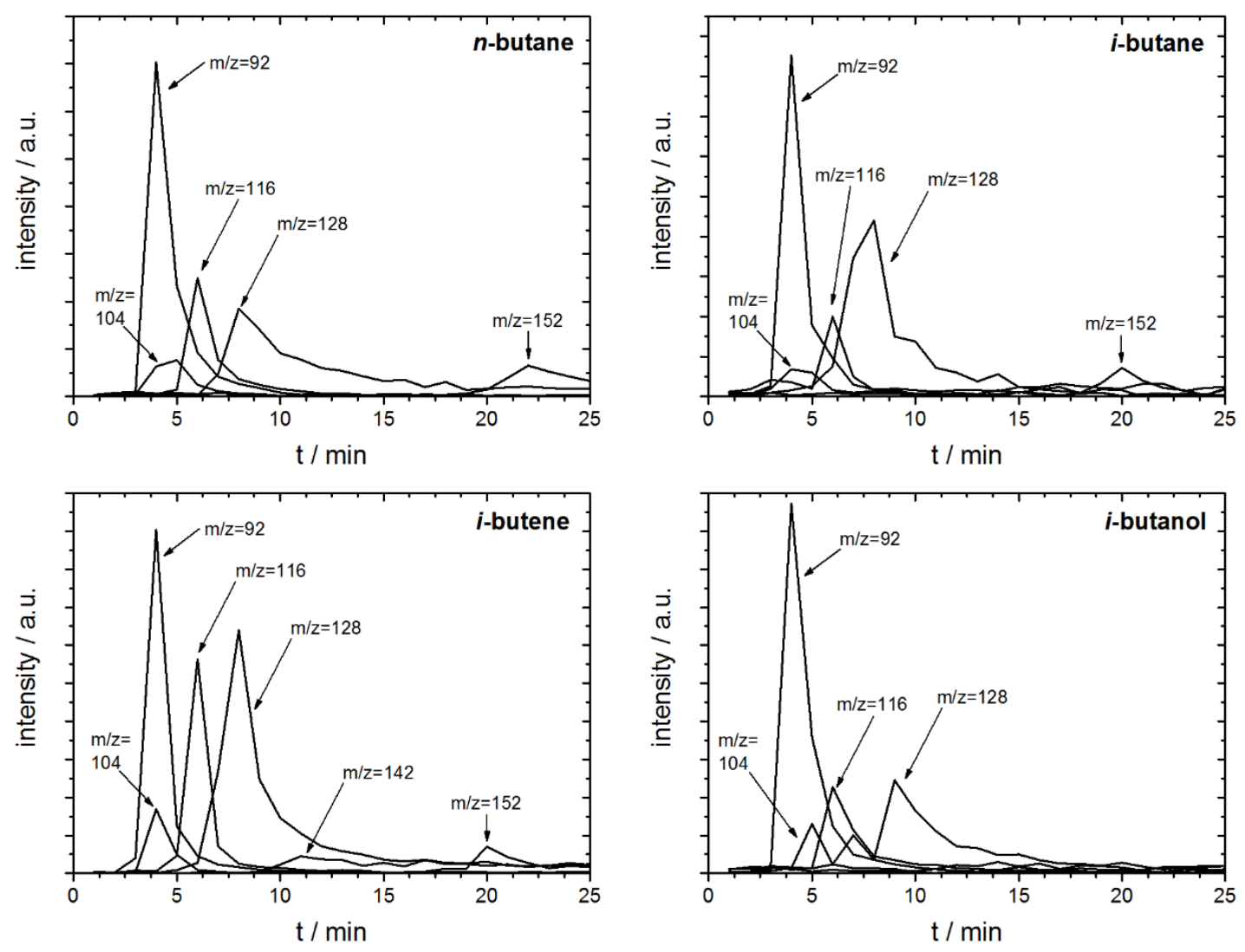


\section{Figure 5: $(290+25=315$ words $)$}

Excerpts of a flame-sampled time-of-flight mass spectrum indicating the presence of fivemembered ring structures and their possible role in molecular-growth reactions. See text for details.
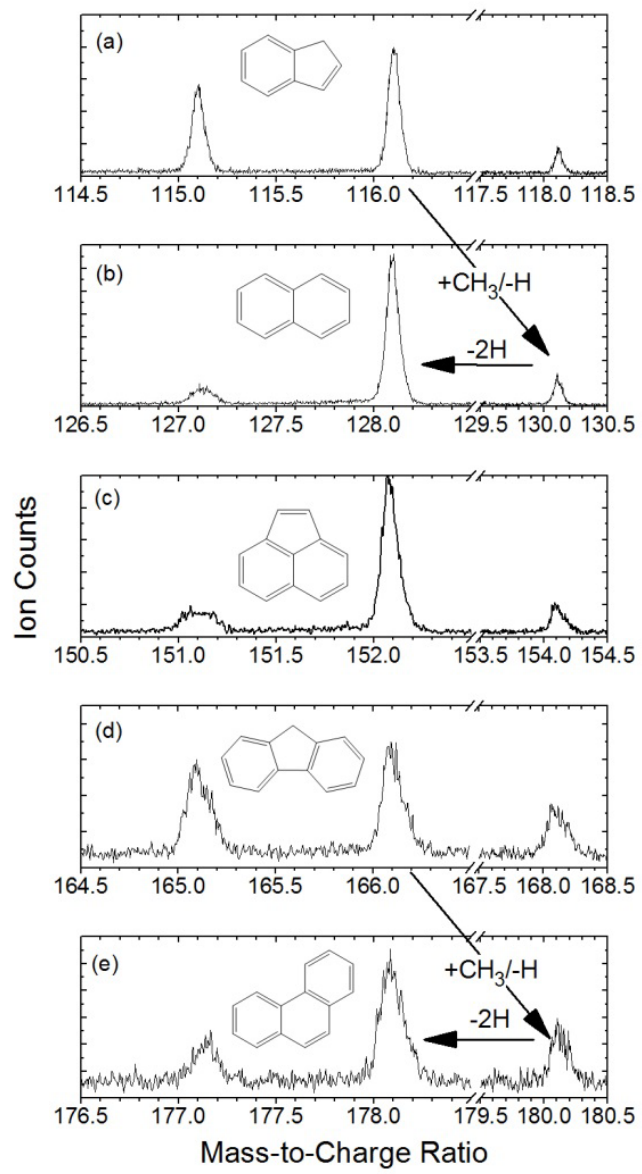
Figure 6: $(601+59=660$ words $)$

HIM micrographs for soot probed from atmospheric-pressure flames of $n$-butane (upper row) and $i$-butanol (bottom). For near-spherical particles (circles and pentagons), the diameter is given. The contrast of the images was enhanced to facilitate visibility of small particles; the used image enhancement procedure is given in the Supplementary Material, together with additional images from the $i$-butane and $i$-butene flames.

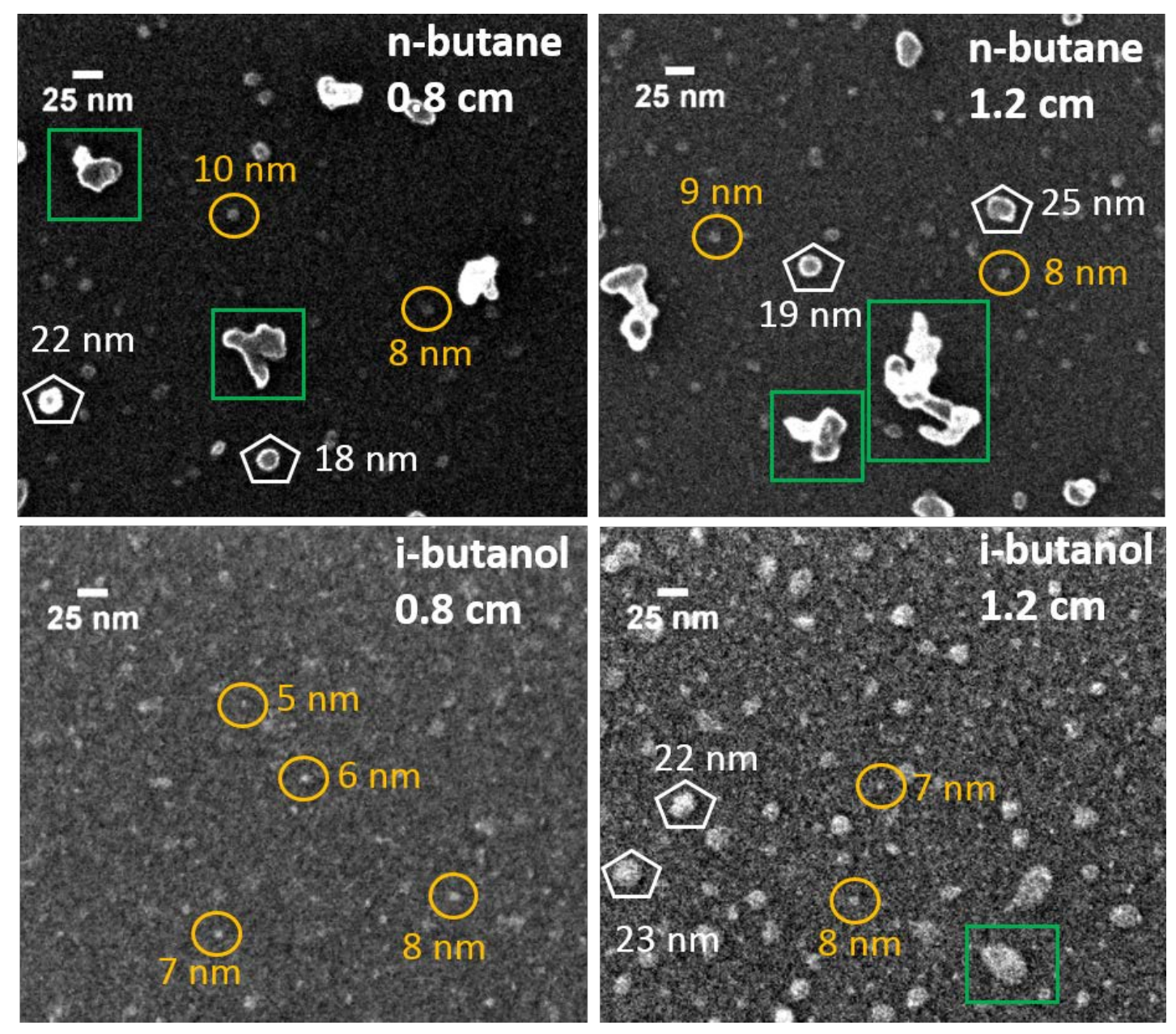




\section{Figure captions:}

\section{Figure 1:}

Flame-sampled mass spectrum from within the atmospheric-pressure opposed-flow $i$-butene diffusion flame.

\section{Figure 2:}

Species profiles as function of distance from the fuel outlet for methyl-addition sequences starting at $m / z=78$ and 128 .

\section{Figure 3:}

Mass spectra and conceivable formation pathways of certain isomers. Naphthalene, methylnaphthalene and acenaphthylene (at $m / z=128,142$, and 152) have been positively identified using the GC experiments. See text for details.

\section{Figure 4:}

GC-MS spectra obtained from the flame zones of the four flames.

\section{Figure 5:}

Excerpts of a flame-sampled time-of-flight mass spectrum indicating the presence of fivemembered ring structures and their possible role in molecular-growth reactions. See text for details.

\section{Figure 6:}

HIM micrographs for soot probed from atmospheric-pressure flames of $n$-butane (upper row) and $i$-butanol (bottom). For near-spherical particles (circles and pentagons), the diameter is given. The contrast of the images was enhanced to facilitate visibility of small particles; the used image enhancement procedure is given in the Supplementary Material, together with additional images from the $i$-butane and $i$-butene flames. 